\title{
PERAN KEPUASAN KERJA DALAM MEMEDIASI PENGARUH SERVANT LEADERSHIP TERHADAP KOMITMEN ORGANISASI
}

\author{
I Made Dwiki ${ }^{1}$ \\ I Gede Riana ${ }^{2}$ \\ ${ }^{1}$ Fakultas Ekonomi dan Bisnis Universitas Udayana (Unud), Bali, Indonesia \\ email: madedwiki@ymail.com
}

\begin{abstract}
ABSTRAK
Tujuan dari penelitian ini untuk menguji peran kepuasan kerja dalam memediasi pengaruh servant leadership terhadap komitmen organisasi karyawan dengan menggunakan rumus slovin sampel yang diambil sebanyak 75 karyawan, melalui teknik analisis jalur (Path analysis). Berdasarkan hasil analisis dapat disimpulkan bahwa servant leadership memiliki pengaruh positif terhadap kepuasan kerja. Kepuasan kerja memiliki pengaruh positif terhadap komitmen organisasional. Servant leadership memiliki pengaruh positif terhadap komitmen organisasional. Kepuasan kerja memediasi pengaruh servant leadership terhadap komitmen organisasional. Implikasi yang dapat diberikan kepada pimpinan perusahaan melalui penerapan servant leadership dapat menjaga rasa kebersamaan di dalam perusahaan dengan saling hormat-menghormati antar atasan dan bawahan serta memberikan penghargaan langsung untuk karyawan yang memiliki kontribusi positif demi kemajuan perusahaan. Melakukan evaluasi terhadap kepuasan kerja yang dirasakan karyawan terkait besaran gaji yang diberikan agar sesuai dengan beban pekerjaan di masing-masing bagian. Meningkatkan sikap komitmen secara bersama dengan menanamkan rasa kebersamaan sehingga karyawan memiliki keinginan ikut mencapai visi misi perusahaan untuk bertahan di dalam perusahaan tanpa memikirkan hal-hal lainnya.
\end{abstract}

Kata kunci : servant leadership, kepuasan kerja, komitmen organisasional

\begin{abstract}
The purpose of this study was to examine the role of job satisfaction in mediating the influence of servant leadership on employee organizational commitment by using the slovin formula of samples taken as many as 75 employees, through path analysis technique. Based on the analysis results can be concluded that servant leadership has a positive effect on job satisfaction. Job satisfaction has a positive effect on organizational commitment. Servant leadership has a positive influence on organizational commitment. Job satisfaction mediates the effect of servant leadership on organizational commitment. Implications that can be given to corporate leaders through the application of servant leadership can maintain a sense of togetherness in the company with mutual respect-respect between superiors and subordinates and provide direct rewards for employees who have a positive contribution for the progress of the company. Evaluate job satisfaction perceived by employee related salary amount given to fit with work load in each part. Enhance commitment attitude together by instilling a sense of togetherness so that employees have the desire to come to achieve the vision of the company's mission to stay in the company without thinking of other things.
\end{abstract}

Keywords: servant leadership, job satisfaction, organizational commitment

\section{PENDAHULUAN}


Sumber daya manusia merupakan aset penting dalam suatu organisasi, karena merupakan sumber yang mengendalikan organisasi serta mempertahankan dan mengembangkan organisasi dalam menghadapi berbagai tuntutan zaman (Fery, 2013). Oleh karena itu komitmen organisasi merujuk kepada keberpihakan dan kesetiaan karyawan kepada perusahaan dan tujuan-tujuan perusahaan (Vania, 2013). Erlan (2013) menyatakan komitmen organisasi sebagai ukuran dari kekuatan identitas dan keterlibatan karyawan dalam tujuan dan nilai-nilai organisasi. Luthans (2006:112) mendefinisikan komitmen organisasi sebagai sebuah sikap yang merefleksikan loyalitas karyawan kepada organisasi dan merupakan suatu proses berkelanjutan dimana anggota organisasi mengungkapkan perhatian mereka terhadap organisasi, terhadap keberhasilan organisasi serta kemajuan yang berkelanjutan (Wike dan Meily, 2012).

Wike dan Meily (2012) menyatakan untuk mencapai tujuan dan menciptakan komitmen organisasi tidak lepas dari peran seorang pemimpin organisasi itu sendiri. Pimpinan memiliki peranan strategis dalam hal mempengaruhi kesanggupan organisasi untuk mencapai tujuannya. Para pemimpin dapat mempengaruhi moral karyawan dengan konsep servant leadership yang melihat kebutuhan pihak lain sebagai prioritas yang utama, baik itu karyawan perusahaan, pelanggan, maupun masyarakat. Manajer Human Resources Development (HRD) PT. Grha Humanindo Manajemen Denpasar saat ini diindikasikan belum sepenuhnya melakukan tindakantindakan untuk menerapkan prinsip-prinsip servant-leadership. Manajer Human Resources Development (HRD) tidak pernah memberikan apresiasi pada karyawan 
yang melakukan pekerjaan dengan baik. Karyawan kurang mendapatkan kesempatan untuk menyampaikan keluhan dan aspirasi. Manajer Human Resources Development (HRD) jarang melakukan sosialisasi apabila terdapat perubahan peraturan, maupun perubahan manajemen dalam perusahaan karena merasa dapat diikuti sepenuhnya oleh karyawannya.

Faktor kepemimpinan servant leadership adalah salah satu faktor yang mempengaruhi komitmen organisasi karyawan, begitupun dengan faktor tingkat kepuasan kerja karyawan yang juga menjadi salah satu hal penting dalam meningkatkan komitmen organisasi karyawan yang memiliki keterkaitan dengan sikap pimpinan (Anwar and Tinton, 2015). Simamora (2008:27) menyatakan kepuasan kerja adalah salah satu faktor ukuran bagaimana pegawai menjalankan kewajibannya. Menurut (Sudarta, 2016) ada dua jenis faktor yang dapat mendorong seseorang dalam bekerja yaitu faktor hygiene dan faktor motivator. Dalam penelitian ini menggunakan kedua teori tersebut karena berhubungan dengan kepuasan kerja.

Anwar and Tinton (2015) menyatakan bahwa kepuasan kerja adalah keadaan emosional karyawan ketika merasakan kesesuaian nilai balas jasa yang diharapkan. Menurut (Robbins and Judge, 2008:102) kepuasan kerja merupakan suatu sikap seseorang terhadap pekerjaan disaat adanya kesesuaian dengan imbalan yang di dapat. Luthans (2011:62) menyatakan faktor-faktor utama yang mempengaruh kepuasan kerja adalah sebagai berikut: pekerjaan itu sendiri, promosi, kelompok kerja, kondisi kerja, upah/gaji, dan pengawasan. Hal yang sama dinyatakan oleh Sudarta (2016) dimana ada beberapa faktor yang mempengaruhi timbulnya kepuasan 
kerja. Pertama, faktor hygiene meliputi kebijaksanaan pimpinan, administrasi, supervisi, kondisi kerja, hubungan interpersonal, uang, status dan keamanan. Kedua, faktor motivator yaitu prestasi, penghargaan, tantangan pekerjaan dan tanggung jawab (Yesika et al., 2011). Kepuasan kerja yang rendah menimbulkan berbagai dampak negatif seperti mangkir kerja, pindah kerja, dan malas bekerja, sebaliknya kepuasan kerja yang tinggi akan mampu meningkatkan efektifitas dan efisiensi kerja sehingga mampu meningkatkan sikap komitmen organisasi karyawan terhadap perusahaan (Anwar and Tinton, 2015).

Fenomena masalah yang terjadi pada karyawan PT. Grha Humanindo Manajemen Denpasar melalui hasil wawancara dengan 10 orang karyawan menyangkut masalah komitmen organisasi dapat dilihat pada tabel 1.1 berikut ini.

\section{Tabel 1 Indikasi Masalah Komitmen Organisasi Pada PT. Grha Humanindo} Manajemen Denpasar

\begin{tabular}{clccc}
\hline No. & \multicolumn{1}{c}{$\begin{array}{c}\text { Indikasi Masalah Komitmen } \\
\text { Organisasi }\end{array}$} & $\begin{array}{c}\text { Terdapat } \\
\text { Masalah } \\
\text { (Orang) }\end{array}$ & $\begin{array}{c}\text { Tidak } \\
\text { Terdapat } \\
\text { Masalah } \\
\text { (Orang) }\end{array}$ & $\begin{array}{c}\text { Jumlah } \\
\text { (Orang) }\end{array}$ \\
\hline 1 & $\begin{array}{l}\text { Keterlibatan kerja sama antar } \\
\text { karyawan }\end{array}$ & 7 & 3 & 10 \\
2 & $\begin{array}{l}\text { Keuntungan finansial gaji, service fee } \\
\text { Kewajiban pekerjaan melebihi }\end{array}$ & 3 & 7 & 10 \\
kemampuan & 6 & 4 & 10 \\
\hline
\end{tabular}

Sumber : Data diolah, 2018

Tabel 1 menjelaskan beberapa masalah komitmen organisasi di PT. Grha Humanindo Manajemen Denpasar dengan hasil wawancara kepada 10 karyawan dapat diketahui kurangnya rasa kerjasama atau saling menghormati antar sesama rekan kerja atau atasan dan bawahan. Masih ada kesenjangan rasa tidakpuas karena 
ada kesenjangan terhadap gaji yang diterima dengan jenis pekerjaan yang diberikan perusahaan, seperti minimnya service fee yang diberikan perusahaan sedangkan karyawan sering bekerja lembur. Pekerjaan yang melebihi kemampuan karyawan sehingga menyebabkan karyawan merasa malas bekerja. Minimnya promosi jabatan yang diterima karyawan bagi karyawan yang berprestasi. Hal-hal ini merupakan masalah yang dapat memicu terjadinya ketidakpuasan karyawan di dalam bekerja, tentu saja akan mempengaruhi komitmen organisasi karyawan terhadap PT. Grha Humanindo Manajemen Denpasar kedepan.

Pentingnya sikap komitmen organisasi bagi PT. Grha Humanindo Manajemen Denpasar, sebagai perusahaan yang bergerak pada usaha pengelolaan tenaga kerja atau pihak penyedia tenaga kerja yang siap memenuhi kebutuhan sumber daya manusia bagi perusahaan-perusahaan rekanannya, manajemen wajib menekankan komitmen organisasi pada karyawan agar dapat bekerja dengan baik di perusahaanperusahaan rekanannya. Komitmen organisasi seseorang terhadap organisasi/ perusahaan seringkali menjadi isu yang sangat penting di dalam dunia kerja. Sayangnya meskipun hal ini sudah sangat umum namun tidak jarang pengusaha maupun karyawan masih belum memahami arti komitmen secara sungguh-sungguh. Padahal pemahaman tersebut sangatlah penting agar tercipta kondisi kerja yang kondusif sehingga perusahaan dapat berjalan secara efisien dan efektif (Adelia et al., 2015).

Peran seorang pemimpin sangatlah diperlukan untuk meningkatkan komitmen organisasi para anggota perusahaan. Kepemimpinan sebagai bagian integral dari 
efektivitas organisasi, maka kualitas dari pemimpin seringkali dianggap sebagai faktor terpenting yang menentukan keberhasilan atau kegagalan organisasi. Untuk menjadi pemimpin yang efektif, seseorang harus dapat mempengaruhi seluruh anggota yang dipimpinnya melalui cara-cara yang positif sehingga menciptakan kepuasan kerja karyawan (Fery, 2013).

Melalui pemaparan masalah yang telah dijabarkan, didukung dengan karya ilmiah dan teori tujuan dari karya ilmiah ini yang hendak dicapai 1) Apakah servant leadership berpengaruh terhadap kepuasan kerja karyawan, 2) Apakah kepuasan kerja karyawan berpengaruh terhadap komitmen organisasi, 3) Apakah servant leadership berpengaruh terhadap komitmen organisasi, 4) Apakah kepuasan kerja karyawan memediasi pengaruh servant leadership terhadap komitmen organisasi.

Luthans (2006:112) mendefinisikan komitmen organisasi sebagai sebuah sikap yang merefleksikan loyalitas karyawan kepada organisasi dan merupakan suatu proses berkelanjutan dimana anggota organisasi mengungkapkan perhatian mereka terhadap organisasi, terhadap keberhasilan organisasi serta kemajuan yang berkelanjutan (Wike dan Meily, 2012). Komitmen organisasi merupakan tanggapan afektif terhadap organisasi. Beberapa ahli mendefinisikan komitmen organisasi dalam bentuk yang berbeda namun memiliki kesamaan arti. Robbins \& Judge (2008:97) komitmen organisasi didefinisikan sebagai suatu keadaan dimana seorang individu memihak organisasi serta tujuan-tujuan dan keinginannya untuk mempertahankan keanggotaannya dalam organisasi.

Dimensi Komitmen Organisasi 
Robbins \& Judge (2008:116) mendefinisikan ada tiga dimensi komitmen organisasi yaitu: Komitmen afektif (affective comitment): keterikatan emosional karyawan, dan keterlibatan dalam organisasi. Komitmen berkelanjutan (continuence commitment): Komitmen berdasarkan kerugian yang berhubungan dengan keluarnya karyawan dari organisasi. Hal ini mungkin karena kehilangan senioritas atas promosi atau benefit. Komitmen normatif (normative commiment): Perasaan wajib untuk tetap berada dalam organisasi karena memang harus begitu; tindakan tersebut merupakan hal benar yang harus dilakukan.

Servant Leadership

Servant Leadership pertama kali dikonsep oleh Greenleaf pada tahun 1998. Karakteristik dari perilaku kepemimpinan yang melayani tumbuh dari nilai-nilai dan keyakinan individu. Nilai-nilai pribadi seperti keadilan dan integritas adalah variabel independen yang menggerakkan perilaku pemimpin yang melayani (Ahmad, 2014). Greenleaf (1998) berpendapat bahwa pemimpin yang melayani dapat mempengaruhi produktivitas dalam situasi nyata sebuah organisasi. Servant leadership yang berorientasi pada kepemimpinan yang melayani, berbasis pengetahuan, partisipatif, aspek tanggung jawab dalam proses, etika dan sosial dapat meredakan skandal atau konflik didalam organisasi.

Indikator Servant Leadership

Berikut ini adalah indikator Servant Leadership yang dikemukakan oleh Dennis (2004) dalam Mustikadewi (2015). Skala pengukuran Servant Leadership 
yaitu Servant Leadership Assement Instrument (SLAI), indikator Servant Leadership adalah sebagai berikut : Kasih Sayang (Love), kepemimpinan yang menyayangi dengan cinta atau kasih sayang. Cinta yang dimaksud adalah melakukan hal yang benar pada waktu yang tepat untuk alasandan keputusan yang terbaik. Pemberdayaan (Empowerment), penekanan pada kerjasama, dalam hal ini mempercayakan kekuasaan pada orang lain, dan mendengarkan saran dari followers. Visi (Vision), arah organisasi dimasa mendatang yang akan diciptakan oleh seorang pemimpin. Visi yang akan menginspirasi tindakan dan membantu membentuk masa depan. Kerendahan Hati (Humility), menjaga kerendahan hati dengan menunjukkan rasa hormat terhadap karyawan dan mengakui kontribusi karyawan terhadap tim. Kepercayaan (Trust), servant-leader adalah orang-orang pilihan yang dipilih berdasarkan suatu kelebihan yang menyebabkan pemimpin tersebut mendapatkan kepercayaan.

\section{Kepuasan Kerja}

Rivai (2006:475), kepuasan kerja pada dasarnya bersifat individual. Setiap individu mempunyai tingkat kepuasan yang berbeda-beda sesuai dengan sistem nilai yang berlaku dalam dirinya. Makin tinggi penilaian terhadap kegiatan dirasakan sesuai dengan keinginan individu, maka makin tinggi kepuasannya terhadap kegiatan tersebut. Dengan kata lain, kepuasan merupakan evaluasi yang menggambarkan seseorang atas perasaan sikapnya senang atau tidak senang, puas atau tidak puas dalam bekerja. Hal yang hampir sama juga dikemukakan oleh Robbins and Judge $(2008$;2) dimana kepuasan kerja diartikan sebagai perasaan senang atau kecewa 
seseorang yang muncul setelah membandingkan antara persepsi/kerjanya terhadap kinerja suatu produk dan harapan-harapannya.

Indikator Kepuasan Kerja

Robbins (2011: 181-182) menjabarkan indikator-indikator yang berkaitan dengan kerja yang menentukan kepuasan kerja, meliputi: Upah dan gaji merupakan balas jasa yang diberikan perusahaan kepada pegawainya berupa uang. Uang bukan hanya memenuhi kebutuhan dasar seseorang melainkan pada akhirnya dapat memberikan kepuasan pada orang tersebut. Pekerjaan dapat memberikan kepuasan bagi seseorang. Jenis pekerjaan yang dapat memberikan kepuasan adalah pekerjaan yang sesuai dengan kemampuan atau sesuai dengan keinginan. Pengawasan sangat diperlukan dalam menjaga keselamatan seseorang. Pengawasan yang dapat dilakukan antara lain peringatan yang tegas, penegakan disiplin, serta pemberian penghargaan pada karyawan yang berprestasi. Promosi merupakan peluang dari kenaikan jabatan seseorang. Kesempatan untuk dapat meningkatkan karir di organisasi menjadi sumber kepuasan seseorang. Sesama rekan sekerja harus saling menghormati dan dapat menciptakan suasana kekeluargaan.

Model Konseptual

Skema model konseptual ini menjelaskan bahwa servant leadership memediasi pengaruh positif komunikasi interpersonal terhadap komitmen organisasi. Untuk lebih jelasnya kerangka pemikiran dapat dilihat pada gambar 2.1 sebagai berikut. Berdasarkan penelusuran path analisis dan hasil-hasil penelitian terdahulu maka model penelitian dapat digambarkan seperti berikut: 


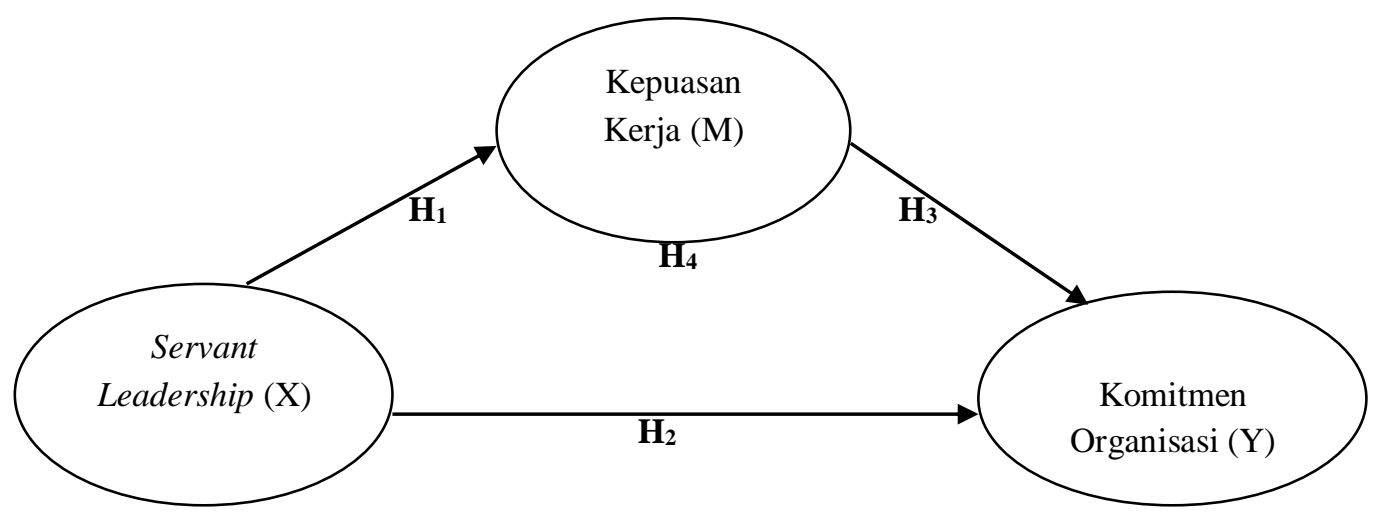

\section{Gambar 1 Kerangka Konseptual}

Rumusan Hipotesis

Beberapa Penelitian sebelumnya telah membuktikan bahwa servant leadership berhubungan dengan kepuasan kerja karyawan. Andes (2015) mengatakan penerapan servant leadership memiliki pengaruh positif dalam menciptakan kepuasan kerja karyawan. Anwar and Tinton (2015) menyatakan kepuasan kerja karyawan dapat tercipta dengan baik melalui peran servant leadership. Hal ini didukung oleh Aditya dan Ayu (2016) bahwa servant leadership memiliki pengaruh positif dalam meningkatkan kepuasan kerja karyawan. Fery et al. (2013) mengatakan penerapan servant leadership memiliki pengaruh positif dalam menciptakan kepuasan kerja karyawan. Asif et al. (2013) menyatakan kepuasan kerja karyawan dipengaruhi secara positif oleh servant leadership. Berdasarkan pemahaman tersebut dapat dirumuskan hipotesis pertama sebagai berikut.

$\mathrm{H}_{1}$ : servant leadership berpengaruh positif dan signifikan terhadap kepuasan kerja. 
Menurut Yesika et al. (2011) kepuasan kerja mempunyai pengaruh positif terhadap komitmen organisasi karyawan dalam menjalankan tugas-tugas yang dibebankan kepadanya. Mustikadewi (2015) mengatakan bahwa kepuasan kerja memiliki keterkaitan positif terhadap komitmen organisasi. Komitmen organisasi akan tercipta apabila setiap karyawan memiliki kepuasan kerja yang baik (Thoyib dan Surachman, 2013). Andes (2015) mengatakan kepuasan kerja memiliki pengaruh positif dalam menciptakan komitmen organisasi. Anwar and Tinton (2015) menyatakan kepuasan kerja karyawan secara langsung berpengaruh positif pada komitmen organisasi. Berdasarkan pemahaman tersebut dapat dirumuskan hipotesis kedua sebagai berikut.

$\mathrm{H}_{2}$ : Kepuasan kerja berpengaruh positif dan signifikan terhadap komitmen organisasi

Menurut Fery et al. (2013) mengatakan bahwa peran servant leadership merupakan salah satu faktor yang dapat memberikan pengaruh positif terhadap komitmen organisasi. Syahfarnas (2014) memberikan pendapat yang sama peran servant leadership memberikan pengaruh positif terhadap komitmen organisasi. Hal ini didukung oleh Asif et al. (2013) servant leadership yang diterapkan oleh seorang pemimpin mampu meningkatkan dan memberikan pengaruh positif terhadap komitmen organisasi. Anwar and Tinton (2015) menyatakan komitmen organisasi dapat tercipta dengan baik melalui peran servant leadership. Hal ini didukung oleh Aditya dan Ayu (2016) servant leadership memiliki pengaruh positif dalam 
meningkatkan komitmen organisasi. Berdasarkan pemahaman tersebut dapat dirumuskan hipotesis pertama sebagai berikut.

$\mathrm{H}_{3}$ : servant leadership berpengaruh positif dan signifikan terhadap komitmen organisasi

Penelitian Anwar and Tinton (2015) menyatakan kepuasan kerja mampu memediasi pengaruh kepemimpinan servant leadership terhadap komitmen organisasi. Sudarta (2016) menyatakan hal yang sama adanya kepuasan kerja karyawan mampu memediasi hubungan positif kepemimpinan servant leadership terhadap komitmen organisasi. Aditya dan Ayu (2016) menyatakan peran kepuasan kerja secara positif memediasi hubungan kepemimpinan dengan peningkatan komitmen organisasi karyawan. Yesika et al (2011) kepuasan kerja mempunyai pengaruh positif dalam memediasi hubungan kepemimpinan servant leadership terhadap komitmen organisasi. Mustikadewi (2015) mengatakan bahwa kepuasan kerja memiliki keterkaitan positif dalam memediasi kepemimpinan servant leadership terhadap komitmen organisasi. Berdasarkan pemahaman tersebut dapat dirumuskan hipotesis kedua sebagai berikut.

$\mathrm{H}_{4}$ : Kepuasan kerja memediasi pengaruh servant leadership terhadap komitmen organisasi

\section{METODE PENELITIAN}

Karya ilmiah ini menggunakan metode asosiatif yang bertujuan untuk mengetahui pengaruh ataupun juga hubungan antara dua variabel atau lebih (Sugiyono, 2013:56). Penelitian ini dilakukan di PT. Grha Humanindo Manajemen 
(GHM). PT. Grha Humanindo Manajemen (GHM) adalah perusahaan yang bergerak di bidang penyedia jasa pekerja outsourcing, yang beralamat Jl Raya Tuban, Komplek Pertokoan Kuta Indah Permai Blok C. No.3. Adapun alasan yang melatarbelakangi peneliti melakukan penelitian karena usaha yang bergerak dibidang jasa saat ini, harus mampu memberikan jaminan atas kualitas layanan kepada klien, dan adanya dukungan dari pendapat ahli yang digunakan dalam studi ini dimana komitmen organisasi ialah faktor pendukung perusahaan dalam meningkatkan gairah kerja karyawan dalam mendukung tujuan perusahaan.

Obyek penelitian adalah suatu hal atau apa saja yang menjadi perhatian dan apa saja yang diteliti (kamus bahasa Indonesia, 2008). Sebagai obyek dalam penelitian adalah komitmen organisasional yang diukur dengan dimensi-dimensi servant leadership, kepuasan kerja. Variabel bebas adalah servant leadership (X), kepuasan kerja (M), dan variabel terikat adalah komitmen organisasional(Y).

Jenis data kuantitatif dan kualitatif yang dipergunakan seperti data jumlah karyawan, jawaban responden terhadap kuisioner dan seperti sejarah perusahaan, struktur organisasi dan aktivitas perusahaan. Sumber data primer dan sekunder yang dipergunakan seperti observasi dan pemberian kuesioner kepada responden dan sejarah berdirinya perusahaan, struktur organisasi perusahaan, dan jumlah karyawan. Jumlah sampel populasi dalam penelitian ini adalah seluruh karyawan PT. Grha Humanindo Manajemen Denpasar Bali sebanyak 308 orang mengenai faktorfaktor yang mempengaruhi komitmen organisasi. Besarnya jumlah sampel karyawan tetap yang didapat ialah 75 orang. Sampel yang akan digunakan berdasarkan metode 
proporsional random sampling karena anggota populasi bersifat homogen sehingga dapat mewakili seluruh populasi yang ada. Data yang dikumpulkan dalam penelitian ini menggunakan metode wawancara dan kuesioner yang diberikan kepada responden yang telah dipilih.

Pengujian Instrumen Penelitian

Uji Validitas dan Uji Reliabilitas

Uji validitas menyatakan sebuah instrumen dikatakan valid jika item yang mempunyai korelasi positif dengan kriterum (skor total) serta korelasi tinggi menunjukkan bahwa item tersebut mempunyai validitas yang tinggi pula. Syarat minimum untuk dianggap memenuhi syarat adalah kalau $r=0,3$ ". Uji reabilitas ditunjukkan dengan angka indeks yang konsistensi suatu alat ukur dalam mengukur gejala yang sama. Uji reabilitas mampu menunjukan sejauh mana instrument dapat dipercaya dan diharapkan. Nilai suatu instrumen dikatakan reliabel bila nilai Alpha Cronbach $\geq 0,6$.

Teknik Analisis Data

Analisis Jalur (Path Analysis)

Teknik analisis data yang digunakan untuk membahas permasalahan dalam penelitian ini adalah analisis jalur. Analisis jalur dikembangkan sebagai metode untuk mempelajari pengaruh, baik secara langsung maupun tidak langsung variabel bebas terhadap variabel tergantung. Analisis ini merupakan salah satu pilihan dalam rangka mempelajari ketergantungan sejumlah variabel di dalam model. Analisis ini merupakan metode yang baik untuk menerangkan apabila terdapat seperangkat data 
yang lebih besar untuk dianalisis dan mencari hubungan kausal dengan langkahlangkah dalam analisis jalur adalah sebagai berikut.

Langkah pertama dalam analisis jalur adalah merancang model berdasarkan konsep teoritis yaitu mengukur variabel servant Leadership (X), berpengaruh terhadap kepuasan kerja (M) dan variabel kepuasan kerja (M), berpengaruh terhadap komitmen organsasional (Y).

Langkah kedua adalah pemeriksaan terhadap asumsi yang melandasi analisis jalur. Pemeriksaan terhadap asumsi yang melandasi yaitu hubungan antar variabel adalah linier dan aditif. Model yang digunakan adalah rekursif yaitu sistem aliran kausal satu arah. Model rekursif apabila memenuhi asumsi-asumsi yaitu antar variabel eksogen saling bebas. Pengaruh kausalitas variabel endogen searah.

Langkah ketiga dalam analisis jalur adalah pendugaan parameter atau perhitungan koefisien path berdasarkan perhitungan koefisien pada gambar diagram path. Langkah ke empat dalam analisis jalur adalah pemeriksaan validitas model. Sah tidaknya suatu hasil analisis tergantung dari terpenuhi atau tidaknya asumsi yang melandasinya. Terdapat dua indikator validitas model di dalam analisis jalur yaitu koefisien determinasi total dan theory triming.

Langkah kelima di dalam analisis jalur adalah melakukan interpretasi hasil analisis. Cara melakukan interpretasi model adalah menginterpretasikan hasil atau nilai parameter yang ada. Koefisien yang tidak signifikan nilainya dianggap tidak ada, sedangkan nilai parameter yang signifikan bisa dilihat berapa yang mempunyai pengaruh langsung dan seberapa besar yang berpengaruh tidak langsung. Dari nilai 
koefisien bisa dilihat variabel mana yang mempunyai pengaruh dominan, mana yang tidak.

Langkah ke enam pengujian hipotesis mediasi dapat dilakukan dengan prosedur yang dikembangkan oleh Sobel (1982) dan dikenal dengan Uji Sobel (Sobel Test). Uji Sobel digunakan dengan menguji kekuatan pengaruh tidak langsung variabel pengetahuan servant leadership (X) terhadap variabel komitmen organisasi (Y) melalui variabel kepuasan kerja (M). Pengaruh tidak langsung variabel servant leadership (X) terhadap variabel komitmen organisasi (Y) melalui variabel kepuasan kerja (M) dihitung dengan cara mengalikan koefisien jalur X terhadap $M$ (a) dengan koefisien jalur M terhadap Y (b) atau ab. Standar error koefisien a dan b ditulis dengan $\mathrm{S}_{\mathrm{a}}$ dan $\mathrm{S}_{\mathrm{b}}$, besarnya standar error tidak langsung (indirect effect) $\mathrm{S}_{\mathrm{ab}}$.

\section{HASIL DAN PEMBAHASAN}

Hasil Uji Instrumen Penelitian

Uji Validitas

Tabel 2 diketahui bahwa masih-masing indikator variabel memiliki nilai person correlation lebih besar dari 0,30, maka ini berarti indikator/pertanyaan yang digunakan layak digunakan untuk mengukur apa yang seharusnya diukur, dan dapat mengungkap data dari variabel yang diteliti secara tepat. 
Tabel 2

Rangkuman Hasil Uji Validitas

\begin{tabular}{|c|c|c|c|c|}
\hline $\mathrm{No}$ & Variabel & Indikator & Korelasi & Keterangan \\
\hline \multirow[t]{5}{*}{1} & Servant leadership $(\mathrm{X})$ & $\mathrm{X} 1.1$ & 0,831 & Valid \\
\hline & & $\mathrm{X} 1.2$ & 0,699 & Valid \\
\hline & & $\mathrm{X} 1.3$ & 0,824 & Valid \\
\hline & & $\mathrm{X} 1.4$ & 0,708 & Valid \\
\hline & & $\mathrm{X} 1.5$ & 0,826 & Valid \\
\hline \multirow[t]{5}{*}{2} & Kepuasan kerja (M) & M1.1 & 0,798 & Valid \\
\hline & & M1.2 & 0,710 & Valid \\
\hline & & M1.3 & 0,795 & Valid \\
\hline & & M1.4 & 0,852 & Valid \\
\hline & & M1.5 & 0,811 & Valid \\
\hline \multirow[t]{3}{*}{4} & Komitmen organisasi $(\mathrm{Y})$ & Y1 & 0,836 & Valid \\
\hline & & Y2 & 0,800 & Valid \\
\hline & & Y3 & 0,892 & Valid \\
\hline
\end{tabular}

Sumber : data diolah, 2018

Uji Reliabilitas

Tabel 3 diketahui bahwa nilai Cronbach's Alpha untuk masing-masing variabel $>0,6$, ini berarti alat ukur tersebut akan memberikan hasil yang konsisten apabila alat ukur tesebut digunakan kembali untuk meneliti obyek yang sama.

Tabel 3

Hasil Uji Reliabilitas

\begin{tabular}{|c|c|c|c|}
\hline No & Variabel & $\begin{array}{c}\text { Cronbach's } \\
\text { Alpha }\end{array}$ & Keterangan \\
\hline 1 & Servant leadership & 0,835 & Reliabel \\
\hline 2 & Kepuasan kerja & 0,848 & Reliabel \\
\hline 3 & Komitmen organisasi & 0,793 & Reliabel \\
\hline
\end{tabular}

Sumber : data diolah, 2018

Hasil Analisis Jalur (Path Analysis)

Penggunaan analisis jalur dimulai dengan pemeriksaan terhadap asumsi yang melandasi yaitu hubungan antarvariabel adalah linier dan aditif. Model yang digunakan rekursif yaitu aliran kausal satu arah, sedangkan model respirokal atau 
aliran kausal dua arah tidak dapat dianalisis. Penilaian terhadap asumsi tersebut dapat digambarkan seperti terlihat pada Gambar diagram path berikut.

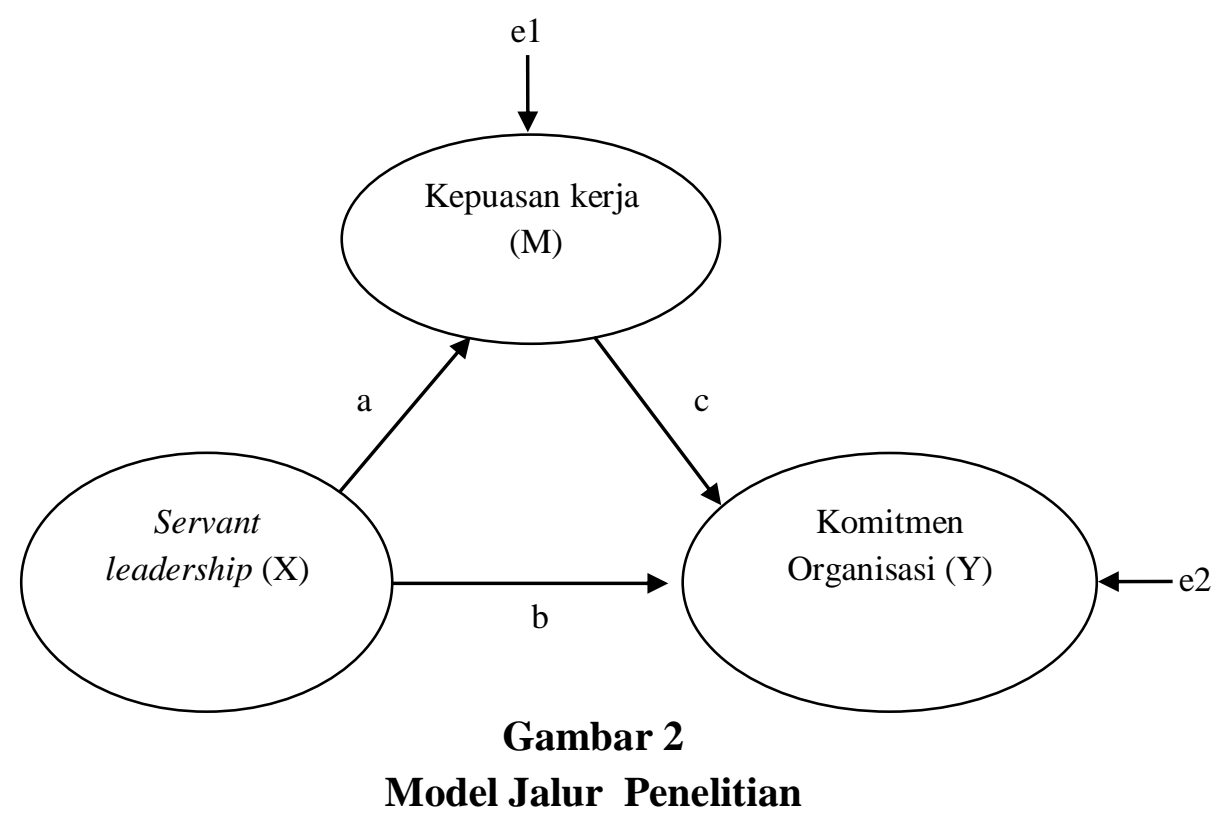

Model tersebut juga dapat dinyatakan dalam bentuk persamaan atau diagram jalur sehingga ada yang menamakan sistem persamaan simultan, atau juga ada yang menyebut model struktural.

Substruktur 1

$\mathrm{M}=\mathrm{aX}+\mathrm{e} 1$

Hasil analisis regresi pada persamaan substruktur 1 dapat dilihat pada Tabel berikut. 


\section{Tabel 4}

Hasil Analisis Jalur Pada substruktur 1

\begin{tabular}{|c|c|c|c|c|c|c|c|c|}
\hline & \multirow[t]{2}{*}{ Model } & \multicolumn{2}{|c|}{$\begin{array}{c}\text { Unstandardized } \\
\text { Coefficients }\end{array}$} & \multirow{2}{*}{$\begin{array}{c}\text { Standardized } \\
\text { Coefficients } \\
\text { Beta }\end{array}$} & \multirow[t]{2}{*}{$\mathrm{t}$} & \multirow[t]{2}{*}{ Sig. } & \multicolumn{2}{|c|}{$\begin{array}{l}\text { Collinearity } \\
\text { Statistics }\end{array}$} \\
\hline & & B & Std.Error & & & & Tolerance & VIF \\
\hline \multirow[t]{2}{*}{1} & (Constant) & 2.738 & 1.245 & & 2.200 & .031 & & \\
\hline & Servant Lead & .845 & 0.063 & .845 & 13.473 & .000 & 1.000 & 1.000 \\
\hline
\end{tabular}

Berdasarkan hasil analisis jalur pada substruktur 1 dapat dibuat persamaan struktural yang terbentuk sebagai berikut.

Substruktur 2

$\mathrm{M}=\mathrm{aX}+\mathrm{e} 1$

$\mathrm{M}=0,845 \mathrm{X}_{1}+\mathrm{e} 1$

$\mathrm{F}$ hitung $=181,524$

$\mathrm{R}^{2}=0,713$

$$
\begin{aligned}
\operatorname{Error} \operatorname{Term}\left(e_{1}\right) & =\sqrt{1-\mathrm{R}^{2}} \\
& =\sqrt{1-0,713^{2}} \\
& =\sqrt{1-0,508} \\
& =\sqrt{0,492} \\
& =0,701
\end{aligned}
$$

\begin{tabular}{|c|c|c|c|c|c|c|c|c|}
\hline & \multirow[t]{2}{*}{ Model } & \multicolumn{2}{|c|}{$\begin{array}{l}\text { Unstandardized } \\
\text { Coefficients }\end{array}$} & \multirow{2}{*}{$\begin{array}{c}\text { Standardized } \\
\text { Coefficients } \\
\text { Beta }\end{array}$} & \multirow[t]{2}{*}{ t } & \multirow[t]{2}{*}{ Sig. } & \multicolumn{2}{|c|}{$\begin{array}{l}\text { Collinearity } \\
\text { Statistics }\end{array}$} \\
\hline & & B & Std.Error & & & & Tolerance & VIF \\
\hline \multirow[t]{3}{*}{1} & (Constant) & -1.423 & 0.552 & & -2.578 & .012 & & \\
\hline & Servant Lead & 287 & 0.050 & .425 & 5.716 & .000 & .287 & 3.487 \\
\hline & Kepuasan & .374 & 0.050 & .554 & 7.446 & .000 & 287 & 3.487 \\
\hline
\end{tabular}

Tabel 5

Hasil analisis regresi substruktur 2

Sumber: data diolah, 2018

Substruktur 2

$$
\begin{aligned}
& \mathrm{Y}=\mathrm{aX}+\mathrm{bM}+\mathrm{e} 2 \ldots \ldots \ldots \ldots \ldots \ldots \ldots \ldots \ldots \\
& \mathrm{Y}=0,287 \mathrm{X}+0,374 \mathrm{M}+\mathrm{e} 2
\end{aligned}
$$


F hitung $=278,948$

$\mathrm{R}^{2}=0,886$

Error Term $\left(e_{1}\right)=\sqrt{1-\mathrm{R}^{2}}$

$$
\begin{aligned}
& =\sqrt{1-0,886^{2}} \\
& =\sqrt{1-0,784} \\
& =\sqrt{0,216} \\
& =0,464
\end{aligned}
$$

Langkah selanjutnya dalam analisis jalur adalah pemeriksaan validitas model. Sah tidaknya suatu hasil analisis tergantung dari terpenuhi atau tidaknya asumsi yang melandasinya. Terdapat dua indikator validitas model di dalam analisis jalur yaitu koefisien determinasi total dan theory triming. Koefisien determinasi total merupakan total keragaman data. Untuk menghitung koefisien determinasi total dapat digunakan persamaan sebagai berikut :

$$
\begin{aligned}
& \mathrm{R}^{2} \mathrm{~m}=1-\left(\mathrm{e}_{1}\right)^{2}\left(\mathrm{e}_{2}\right)^{2} \ldots \ldots \ldots \ldots . . \\
& \mathrm{R}^{2} \mathrm{~m}=1-(0,701)^{2}(0,464)^{2} \\
& \mathrm{R}^{2} \mathrm{~m}=1-(0,491)(0,215) \\
& \mathrm{R}^{2} \mathrm{~m}=1-0,105 \\
& \mathrm{R}^{2} \mathrm{~m}=0,895
\end{aligned}
$$

Berdasarkan hasil perhitungan koefisien determinasi total di dapat nilai sebesar $\left(\mathrm{R}^{2} \mathrm{~m}=0,895\right)$. Hal ini berarti bahwa keragaman data yang dapat dijelaskan oleh model adalah sebesar $89,5 \%$ atau dengan kata lain variasi nilai yang terkandung di dalam data dapat menjelaskan model yang digunakan sebesar $89,5 \%$. Sedangkan sisanya sebesar 10,5\% dijelaskan oleh variabel lain yang tidak digunakan di dalam model dan error. 


\section{Hasil Pengujian Hipotesis}

Pengujian hipotesis dilakukan dengan uji $\mathrm{t}(\mathrm{t}$-test) pada masing-masing jalur pengaruh antara variabel dependen dengan variabel independen. Hasil pengujian hipotesis dengan menggunakan analisis jalur tersebut dapat dijelaskan sebagai berikut (Tabel 4 dan Tabel 5).

Hipotesis 1: Servant leadership berpengaruh positif signifikan terhadap kepuasan kerja karyawan. Hasil analisis jalur dengan menggunakan model regresi mendapatkan hasil koefisien $\beta_{1}$ (positif) sebesar 0,845 dengan t statistik sebesar 13,473, dengan demikian hipotesis 1 diterima. Hal ini berarti bahwa semakin baik penerapan servant leadership, maka kepuasan kerja karyawan pada PT. Grha Humanindo Manajemen akan semakin meningkat.

Hipotesis 2: Kepuasan kerja berpengaruh positif signifikan terhadap komitmen organisasi. Hasil analisis jalur dengan menggunakan model regresi mendapatkan hasil koefisien $\beta_{2}$ (positif) sebesar 0,374 dengan $t$ statistik sebesar 7,446, dengan demikian hipotesis 2 diterima. Hal ini berarti bahwa semakin baik kepuasan kerja karyawan, maka komitmen organisasi karyawan pada PT. Grha Humanindo Manajemen akan semakin meningkat.

Hipotesis 3: Servant leadership berpengaruh positif signifikan terhadap komitmen organisasi. Hasil analisis jalur dengan menggunakan model regresi mendapatkan hasil koefisien $\beta_{3}$ (positif) sebesar 0,287 dengan $t$ statistik sebesar 5,716, dengan demikian hipotesis 3 diterima. Hal ini berarti bahwa semakin baik 
penerapan kepemimpinan servant leadership, maka komitmen organisasi karyawan pada PT. Grha Humanindo Manajemen akan semakin meningkat.

Uji Sobel

Dari hasil perhitungan didapatkan perbandingan nilai z hitung sebesar 5,81> z tabel sebesar 1,96, maka Ho diterima dan Hi ditolak. Artinya servant leadership berpengaruh positif signifikan terhadap komitmen organisasi melalui kepuasan kerja pada karyawan di PT. Grha Humanindo Manajemen, sehingga dapat dikatakan bahwa kepuasan kerja merupakan variabel mediasi pengaruh servant leadership terhadap komitmen organisasi.

Pembahasan Hasil Penelitian

Berdasarkan hasil dari koefisien jalur pada hipotesis penelitian, maka dapat digambarkan hubungan kausal antar variabel servant leadership (X), kepuasan kerja (M) terhadap komitmen organisasi (Y). Perhitungan pengaruh antar variabel dirangkum dalam Tabel 4.13.

Tabel 6 Pengaruh Langsung dan Pengaruh Tidak Langsung serta Pengaruh Total Servant Leadership (X), Kepuasan Kerja (M), dan Komitmen Organisasi (Y)

\begin{tabular}{llccc}
\hline & $\begin{array}{c}\text { Pengaruh } \\
\text { Variabel }\end{array}$ & $\begin{array}{c}\text { Pengaruh } \\
\text { Langsung }\end{array}$ & $\begin{array}{c}\text { Pengaruh Tidak Langsung M } \\
(\mathrm{p} 1 \mathrm{x} \mathrm{p3)}\end{array}$ & Pengaruh Total \\
\hline $\mathrm{P} 1$ & $\mathrm{X} \rightarrow \mathrm{M}$ & 0,845 & - & 0,845 \\
$\mathrm{P} 2$ & $\mathrm{M} \rightarrow \mathrm{Y}$ & 0,374 & - & 0,374 \\
$\mathrm{P} 3$ & $\mathrm{X} \rightarrow \mathrm{Y}$ & 0,287 & - & 0,287 \\
$\mathrm{P} 4$ & $\mathrm{X} \rightarrow \mathrm{M} \rightarrow \mathrm{Y}$ & 0,374 & 0,242 & 0,616 \\
\hline
\end{tabular}

Sumber: data diolah, 2018 
Hasil uji parsial menunjukan bahwa servant leadership berpengaruh positif dan signifikan terhadap kepuasan kerja. Hal ini berarti variabel servant leadership memiliki hubungan positif erat dan signifikan dengan kepuasan kerja.

Hasil uji parsial menunjukan bahwa kepuasan kerja berpengaruh positif dan signifikan terhadap komitmen organisasi. Hal ini berarti variabel kepuasan kerja memiliki hubungan positif erat dan signifikan dengan komitmen organisasi.

Hasil uji parsial menunjukan bahwa servant leadership berpengaruh positif dan signifikan terhadap komitmen organisasi. Hal ini berarti variabel servant leadership memiliki hubungan positif erat dan signifikan dengan komitmen organisasi.

Hasil uji mediasi menyatakan kepuasan kerja mampu memediasi pengaruh servant leadership terhadap komitmen organisasi. Hal ini berarti hubungan positif antara servant leadership dan komitmen organisasi mampu di mediasi oleh kepuasan kerja.

\section{SIMPULAN DAN SARAN}

Berdasarkan pada pembahasan pada bab-bab sebelumnya, maka adapun halhal yang dapat disimpulkan yaitu servant leadership memiliki pengaruh positif dan signifikan terhadap kepuasan kerja karyawan di PT. Grha Humanindo Manajemen. Kepuasan kerja memiliki pengaruh positif dan signifikan terhadap komitmen organisasi karyawan di PT. Grha Humanindo Manajemen. Servant leadership memiliki pengaruh positif dan signifikan terhadap komitmen organisasi karyawan di PT. Grha Humanindo Manajemen. Kepuasan kerja memediasi pengaruh servant 
leadership terhadap komitmen organisasi karyawan di PT. Grha Humanindo Manajemen.

Berdasarkan simpulan, saran-saran yang dapat diberikan kepada pihak manajemen PT. Grha Humanindo Manajemen yang diwakili oleh pimpinannya melalui penerapan sikap servant leadership untuk menjaga rasa kebersamaan di dalam perusahaan dengan saling hormat-menghormati antar atasan dan bawahan serta memberikan penghargaan langsung seperti kompensasi, bonus dan kenaikan jabatan untuk karyawan yang memiliki kontribusi positif demi kemajuan perusahaan. Melakukan evaluasi terhadap kepuasan kerja yang dirasakan karyawan dimana penilaian mereka terhadap gaji yang diberikan perusahaan masih minim. Hal ini tentu harus menjadi perhatian dari pihak perusahaan dengan mengadakan evaluasi ulang terkait besaran gaji yang diberikan agar sesuai dengan beban pekerjaan di masingmasing bagian. Meningkatkan sikap secara bersama mengenai komitmen organisasi karyawan terhadap perusahaan dengan menanamkan rasa kebersamaan sehingga karyawan memiliki keinginan ikut mencapai visi misi perusahaan untuk bertahan di dalam perusahaan tanpa memikirkan hal-hal seperti keuntungan finansial dan pekerjaan yang ditawarkan di tempat lain.

\section{REFERENSI}

Abdu Ja'afaru Bambale, 2014. Relationship Between Servant Leadership and Organizational Citizenship Behaviors: Review of Literature and Future Research Directions. Journal of Marketing and Management. 5(1): h: 1-16 
Adelia Maris, Wiji Utami, Dewi Prihatini, 2015. Pengaruh Servant Leadership dan Kepribadian terhadap Organizational Citizenship Behavior dalam Meningkatkan Kinerja Guru di Sekolah Dasar Al-Baitul Amien (Full Day School) Jember. Artikel Ilmiah Mahasiswa. 3(1): h: : 1-7

Aditya Prabandewi, Putu., Ayu Desi Indrawati. 2016. Pengaruh Kepuasan Kerja, Komitmen Organisasi dan Gender Terhadap Organizational Citizenship Behaviors di PT. BPR Pedungan. Jurnal Manajemen Unud. 5(1): h: 65176547

Ahmad Zubaidi, 2014. The Influence Of Servant Leadership and Bureaucracy Apparatus Behavior to The Service Performance In Resettlement Area in DKI Jakarta. The International Journal of Social Sciences. 27(1): h: 1125

Andes Parlin, author. 2015. Pengaruh Servant Leadership terhadap kepuasan kerja karyawan Kantor Pelayanan Pajak di Jakarta. Jurnal Manajemen dan Kewirausahaan. 3(1): h: 1-12

Anwar Prabu Mangkunegara, Tinton Rumbungan Octorend. 2015. Effect of Work Discipline, Work Motivation and Job Satisfaction on Employee Organizational Commitment in the Company (Case Study in PT. Dada Indonesia). Universal Journal of Management. 3(8): 318-328

Asif Shahzad, Riffat Abbas Rizvi, Aamer Waheed, Aamer Waheed, Imran Khan, Sardar M. Usman, Nabila Nazir, Ghazala Amin and Talat Mahmood Kiyani, 2013. Linking Servant Leadership with Organizational Citizenship Behavior through Trust: An Embryonic Structural Modelling Approach. European Journal of Social Sciences. 39(2): h: 273-284

Baron, R.M. and Kenny, D.A. 1986. The Moderator-Mediator Variable Distinction in Social Psychological Research: Conceptual, strategic, and statistical considerations. Journal of Personality and Social Psychology. 51(6): 1173-1182

Bright Mahembe and Amos S. Engelbrecht, 2014. The Relationship Between Servant Leadership, Organisational Citizenship Behaviour and Team Effectiveness. SA Journal of Industrial Psychology, 40(1): h: 1-10

Cem Gucel and Suat Begec, 2012. The Effect of the Servant Leadership on Organizational Citizenship Behavior: Case Study of A University. International Journal Of Social Sciences and Humanity Study. 4(1): h: $107-116$ 
Erlan Bakiev, 2013. The Influence of Interpersonal Trust and Organizational Commitment on Perceived Organizational Performance. Journal of Applied Economics and Business Researce. 3(3): h: 166-180

Fery Handi Putra, 2013. Analisis Pengaruh Komunikasi Interpersonal, Lingkungan Kerja Fisik dan Disiplin Kerja terhadap Kinerja Pegawai Perpustakaan IAIN Iman Bonjol Padang. Artikel Tesis Manajemen Universitas Bung Hatta. pp: 1-13

Ghozali, Imam, 2011. Aplikasi Analisis Multivariate Dengan Program SPSS. Edisi Kedua.Semarang : Bagian Penerbit Universitas Diponogoro.

Greenleaf, R. K. 1998. Servant Leadership: A Journey into the Nature of Legitimate Power and Greatness. New York: Paulist Press

Haider Raza Abid, Amir Gulzar, and Waqar Hussain, 2015. The Impact of Servant Leadership on Organizational Citizenship Behaviors with the Mediating Role of Trust and Moderating role of group cohesiveness "A Study of public Sector of Pakistan". International Journal of Academic Research in Business and Social Sciences. 5(3): h:234-242

Handoko T. Hani. 2006. Manajemen Personalia dan Sumber Daya Manusia. Edisi 2, Yogyakarta : BPFE UGM.

Hassan Zarei Matin, Golamreza Jandaghi, Fateme Haj Karimi, and Ali Hamidizadeh, 2010. Relationship between Interpersonal Communication Skills and Organizational Commitment (Case Study: Jahad Keshavarzi and University of Qom, Iran). European Journal of Social Sciences. 13(3): h: 387-398

Kurnia Atdi Anto, 2015. The Mediating Role of Organizational Commitment In Influence Relationships Between Interpersonal Communication and Emotional Intelligence Toward Employee Performance. International Journal of Business, Economics and Law. 7(2): h: 47-56

Lora Reed, 2015. Servant Leadership, Followership, and Organizational Citizenship Behaviors in 9-1-1 Emergency Communications Centers: Implications of a National Study. International Journal of Servant Leadership: Theory and Practice. 2(1): h: 71-94

Luthans, Fred, 2011, Perilaku Organisasi, Edisi kesepuluh, Penerbit Andi Offset 
Mustikadewi Kartikarini, 2015. Pengaruh Servant Leadership dan kepuasan kerja terhadap Organizational Citizenship Behaviour (OCB) Karyawan Hotel Bintang-2 di Yogyakarta. Skripsi Manajemen Universitas Negeri Yogyakarta. 3(5): h:1-144

Preacher, K. J. dkk. 2007. "Addressing Moderated Mediation Hypotheses: Theory, Methods, and Prescriptions". Multivariate Behavioral Research

Redi Setiawan, I Gede dan Sudharma, Nyoman, 2015. Pengaruh Kepemimpinan Terhadap Komitmen Organisasi Dimediasi oleh Komunikasi Organisasi Pada PT. Bank Antar Daerah. Jurnal Manajemen Unud. 4(12): h: 40194046.

Robbins, Stephen P., 2011. Perilaku Organisasi, Jilid I, PT. Prenhallindo, Alih Bahasa: Hadyana Pujaatmaka, Jakarta

Robbins, S.P., and Judge, T.A. 2008. Perilaku Organisasi, Edisi Kedua Belas, Jakarta: Salemba Empat

Simamora, H. 2008. Manajemen Sumber Daya Manusia. Jakarta: Bagian Penerbit STIE YKPN.

Sugiyono. 2013. Metode Penelitian Kuantitatif Kualitatif dan R\&D. Bandung: Alfabeta.

Sudarta, I Dewa Nyoman., 2016. Pengaruh Servant Leadership terhadap Organizational Citizenship Behavior dengan mediasi Kepuasan Kerja (Studi Pada Guru Tetap Di Sekolah Kristen Harapan Denpasar). Tesis Universitas Udayana

Suyana Utama, Made. 2007. Buku ajar Aplikasi Analisis Kuantitatif. Denpasar: Fakultas Ekonomi Universitas Udayana

Syahfarnas Adi Putrantoro, 2014. Pengaruh Kepemimpinan, Komitmen Organisasi dan Komunikasi Interpersonal terhadap Organizational Citizenship Behavior (OCB) Anggota Rotaract Club Semarang. Skripsi Ekonomika dan Bisnis Universitas Diponegoro. pp:1-61

Thoyib, Armanu dan Surachman.2013. Peran Organizational Citizenship Behavior sebagai Mediator Pengaruh Kepuasan Kerja, Lingkungan Kerja dan Komitmen Organisasi terhadap Kinerja Karyawan. Jurnal Aplikasi Manajemen. 1(4): h: 547-557 
Tiur Asi Siburian, 2013. The Effect of Interpersonal Communication, Organizational Culture, Job Satisfaction, and Achievement Motivation to Organizational Commitment of State High School Teacher in the District Humbang Hasundutan, North Sumatera, Indonesia. International Journal of Humanities and Social Science. 3(12): h: 247-264

Trompenaars, F. \& Voerman, E. 2010. Harnessing the Strength of the World's Most Powerful Management Philosophy: Servant-Leadership across cultures. New York, NY: McGraw-Hill.

Vania Claresta Prabowo dan Roy Setiawan, 2013. Pengaruh Servant Leadership dan Komitmen Organisasional Karyawan terhadap Organizational Citizenship Behavior pada Blue Bird Group Surabaya. Jurnal Agora. 1(3): h: 1-12

Wike Santa Mira dan Meily Margaretha, 2012. Pengaruh Servant Leadership terhadap Komitmen Organisasional dan Organizational Citizenship Behavior. Jurnal Agora. 11(2): h: 99-116

Yesika Yuniar, I.G.A.A, Nurtjahjanti, Harlina, Rusmawati, Diana. 2011. Hubungan Antara Kepuasan Kerja dan Resiliensi dengan Organizational Citizenship Behavior (OCB) Pada Karyawan Kantor Pusat PT. BPD BALI. Jurnal Psikologi Undip, 9(1): h:11-20. 